\title{
Sphingosine kinase 1 and 2 regulate the capacity of mesangial cells to resist apoptotic stimuli in an opposing manner
}

\author{
Lotte P. Hofmann",2, Shuyu Ren', Stephanie \\ Schwalm ${ }^{1,2}$, Josef Pfeilschifter ${ }^{2}$ and \\ Andrea Huwiler ${ }^{1, *}$ \\ ${ }^{1}$ Institute of Pharmacology, University of Bern, \\ Friedbühlstrasse 49, CH-3010 Bern, Switzerland \\ ${ }^{2}$ Pharmazentrum Frankfurt/ZAFES, Klinikum der Johann \\ Wolfgang Goethe-Universität, Theodor-Stern-Kai 7, \\ D-60590 Frankfurt am Main, Germany \\ ${ }^{*}$ Corresponding author \\ e-mail: huwiler@pki.unibe.ch
}

\begin{abstract}
Sphingosine kinases (SKs) are key enzymes regulating the production of sphingosine-1-phosphate (S1P), which determines important cell responses including cell growth and death. Here we show that renal mesangial cells isolated from wild-type, SK-1/-, and SK-2-- mice show a differential response to apoptotic stimuli. Wildtype mesangial cells responded to staurosporine with increased DNA fragmentation and caspase-3 processing, which was enhanced in SK-1/- cells. In contrast, SK-2-cells were highly resistant to staurosporine-induced apoptosis. Furthermore, the basal phosphorylation and activity of the anti-apoptotic protein kinase B (PKB) and of its substrate Bad were decreased in SK-1/- but not in SK-2 $2^{-/}$cells. Upon staurosporine treatment, phosphorylation of $\mathrm{PKB}$ and $\mathrm{Bad}$ decreased in wild-type and $\mathrm{SK}-1^{-/-}$cells, but remained high in SK-2/- cells. In addition, the anti-apoptotic Bcl- $\mathrm{X}_{\mathrm{L}}$ was significantly upregulated in SK-2-/- cells, which may further contribute to the protective state of these cells. In summary, our data show that SK-1 and SK-2 have opposite effects on the capacity of mesangial cells to resist apoptotic stimuli. This is due to differential modulation of the PKB/Bad pathway and of $\mathrm{Bcl}-\mathrm{X}_{\mathrm{L}}$ expression. Thus, subtype-selective targeting of SKs will be critical when considering these enzymes as therapeutic targets for the treatment of inflammation or cancer.
\end{abstract}

Keywords: apoptosis; ceramide; mesangial cells; sphingosine-1-phosphate; sphingosine kinase knockout mice.

\section{Introduction}

Although sphingolipids exert their main function as structural components of cellular membranes, it has become clear that some sphingolipid species also have critical functions as signalling molecules and regulate a variety of physiological and pathophysiological processes such as cell growth and differentiation, cell migration and adhesion, and apoptosis (Huwiler et al., 2000; Futerman and Hannun, 2004; Huwiler and Pfeilschifter, 2006).

Sphingomyelin is the main precursor of this class of signalling molecules. Upon exposure of cells to various stress factors such as proinflammatory cytokines, oxidative and nitrosative stress, UV- and $\gamma$-irradiation, and chemotherapeutics, sphingomyelinases are activated and hydrolyse sphingomyelin to generate ceramide. Ceramide is further degraded by ceramidases to sphingosine, which in turn serves as a substrate for sphingosine kinases (SKs) to generate sphingosine-1-phosphate (S1P). In contrast to ceramide and sphingosine, which both can trigger an apoptotic cell response, S1P acts to counterbalance this response and stimulates cell proliferation and protects cells from apoptosis. This has led to the hypothesis of a cellular sphingolipid rheostat in which ceramide and S1P counter-regulate each other's functions (Hait et al., 2006).

SKs are critical enzymes regulating the cellular levels of S1P and thus may ultimately control cell fate. SKs are ubiquitously expressed and exist as two subtypes, SK-1 and SK-2 (Alemany et al., 2007). The physiological functions of these two isoforms are still not fully clear. SK-1 has been attributed a key function in cell proliferation and migration, and upregulation of SK-1 mRNA has been reported for several tumour tissues and cell lines (French et al., 2003; Döll et al., 2005, 2007; Alemany et al., 2007). In line with this, recently developed inhibitors of SK-1 are effective in reducing tumour cell growth in vitro and tumour growth in mice (French et al., 2003, 2006). In contrast, SK-2 has been attributed a pro-apoptotic function based on cellular transfection experiments (Liu et al., 2003). SK-2 contains a BH3 domain, which was reported to interact with $\mathrm{Bcl}-\mathrm{X}_{\mathrm{L}}$ and inhibit its protective potential, consequently resulting in cell apoptosis. By interrupting the $\mathrm{SK}-2 / \mathrm{Bcl}-\mathrm{X}_{\mathrm{L}}$ interaction by site-directed mutagenesis of $\mathrm{Leu}^{219}$ in murine SK-2, Bcl- $\mathrm{X}_{\mathrm{L}}$ could exert its full protective effect and apoptosis was prevented (Liu et al., 2003). Furthermore, overexpression of SK-2 in various murine and human cell lines was shown to block DNA synthesis (Igarashi et al., 2003; Okada et al., 2005), which was abrogated by mutation of $\mathrm{Arg}^{93}$ and $\mathrm{Arg}^{94}$ of SK-2 (Igarashi et al., 2003).

In the present study we used renal mesangial cells isolated from wild-type, SK-1-deficient or SK-2-deficient mice and exposed them to the potent apoptotic trigger staurosporine. We show that SK-1-deficient cells are more prone to apoptosis. In contrast, SK-2-deficient cells are highly protected from staurosporine-induced apoptosis. Furthermore, the PKB/Bad signalling cascade was 
poorly activated in cells lacking SK-1, whereas cells lacking SK-2 exhibited robust PKB/Bad activation and constitutive upregulation of anti-apoptotic $B c l-X_{L}$.

\section{Results}

\section{Characterisation of primary cultures of mesangial cells isolated from SK-deficient mice}

To study the cellular functions of SK-1 and SK-2, we used primary cultures of renal mesangial cells from SK1-deficient, SK-2-deficient and C57BL/6 control mice. Mesangial cells cultured from glomeruli isolated from kidneys of SK-1-deficient and SK-2-deficient mice showed no mRNA or protein expression of the corresponding knockout enzyme compared to wild-type C57BL/6 cells (data not shown).

\section{Differential response to apoptotic stimulation of mesangial cells derived from SK-1 and SK-2 knockout mice}

To evaluate whether SK-1 and/or SK-2 have a relevant function in the apoptotic machinery, we investigated the influence of SK-1 and SK-2 deficiency in mesangial cells on DNA fragmentation induced by staurosporine treatment.

Stimulation of wild-type mesangial cells with low doses (10 and $30 \mathrm{~nm}$ ) of staurosporine led to a dose-dependent increase in DNA fragmentation (Figure 1A). In SK-1-deficient mesangial cells, staurosporine evoked a significantly higher amount of DNA fragmentation compared to wild-type cells (Figure 1A). In contrast, SK-2-deficient cells showed considerably less DNA fragmentation upon staurosporine treatment than wild-type cells (Figure 1A). As an additional early marker of apoptosis, phosphatidyl serine exposure on the outer leaflet of the plasma membrane was measured by flow cytometry with detection of annexin V-FITC and 7-aminoactinomycin (7AAD) staining. As observed in Figure 1B, annexin V-FITC binding to apoptotic cells strongly increased in SK-1-deficient cells, but drastically decreased in SK-2-deficient cells. These data suggest opposite cellular functions of SK-1 and SK-2 in the regulation of mesangial cell apoptosis. SK-1 may exert a cell protective effect, but still allows staurosporine to induce apoptosis. Deletion of SK-1 leads to loss of this protection, which allows a higher rate of apoptosis by an apoptotic trigger. In contrast, depletion of SK-2 either removes a harmful signal or induces a protective mechanism and strongly prevents staurosporine-induced apoptosis.

To determine whether the altered DNA fragmentation observed in SK-1 and SK-2 knockout cells is also detected in the apoptosis signalling cascade, caspase-3 processing was investigated. Caspase- 3 is considered an executioner caspase located far downstream in the apoptotic event, but still preceding DNA fragmentation (Boatright and Salvesen, 2003). Western blot analyses of

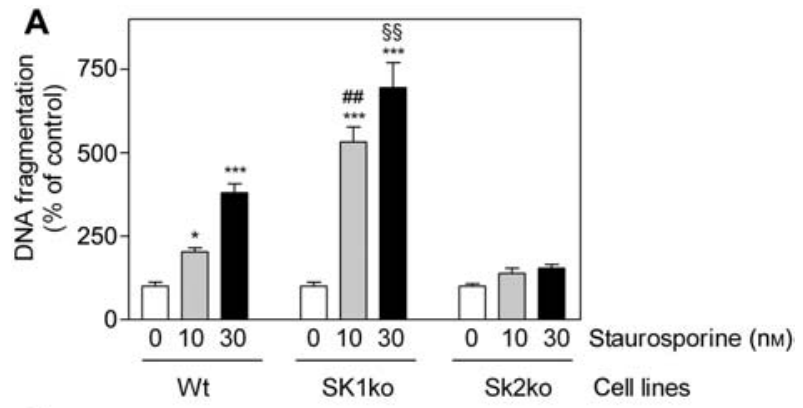

B

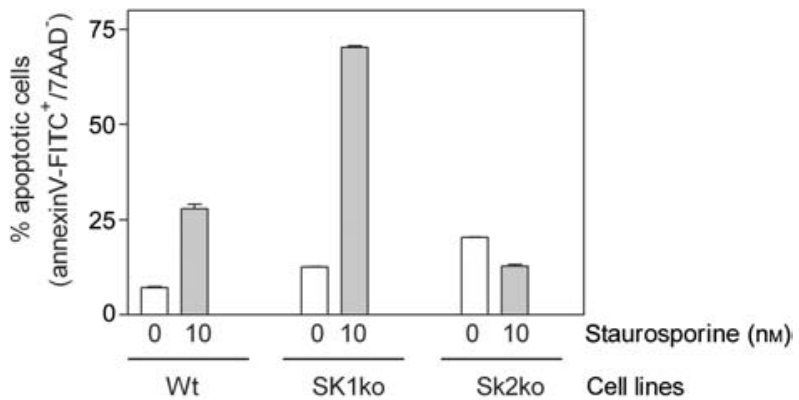

C

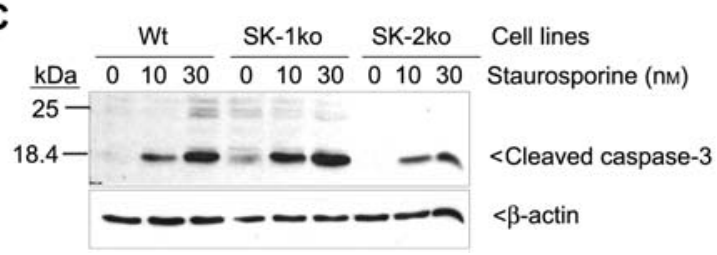

Figure 1 Effect of staurosporine on DNA fragmentation, annexin V-FITC binding, and caspase-3 processing in wild-type, SK1-deficient and SK-2-deficient mouse mesangial cells.

Quiescent mouse mesangial cells isolated from either wild-type (Wt), SK-1-deficient (SK1ko) or SK-2-deficient mice (SK2ko) were stimulated for $6 \mathrm{~h}$ with either vehicle (0) or the indicated concentrations of staurosporine in the presence of $1 \%$ FBS. Then cells were scraped and subjected to a DNA fragmentation ELISA (A), flow cytometry with detection of annexin V-FITC and 7AAD staining (B), or SDS-PAGE and Western blot analysis of cleaved caspase-3 (C, upper panel) or $\beta$-actin (C, lower panel) at dilutions of 1:1000 and 1:10 000, respectively, as described in the materials and methods section. Data in $(A)$ are expressed as a percentage of control values and are mean $\pm \operatorname{SD}(n=3)$. ${ }^{*} p<0.05,{ }^{* \star *} p<0.001$ significantly different compared to wild-

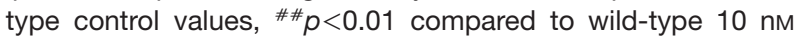
staurosporine values, $s s p<0.01$ compared to wild-type $30 \mathrm{~nm}$ staurosporine values. Results in (B) show the percentage apoptotic cells (annexin V-FITC-positive and 7AAD-negative) and are the mean for two independent experiments. Data in (C) are representative of four independent experiments giving similar results.

the different primary cell cultures stimulated with staurosporine were performed. As observed in Figure 1C, cleaved caspase-3, which represents the active enzyme and runs at a size of $18 \mathrm{kDa}$, increased upon staurosporine treatment of wild-type cells, confirming many previous reports that staurosporine is able to activate caspase-3 (Yue et al., 1998). In SK-1-deficient cells, staurosporine-activated caspase-3 was enhanced compared to wild-type cells, whereas caspase- 3 was activated to a lesser extent in SK-2-deficient cells (Figure 1C). $\beta$-Actin expression was similar in all three primary cell cultures, confirming equal loading. 


\section{Expression profiles of the anti-apoptotic factors PKB, Bad, Bcl-2 and $\mathrm{Bcl}-\mathrm{X}_{\mathrm{L}}$ in SK-1- and SK-2-deficient cells}

To investigate whether the altered rate of apoptosis in SK-1- and SK-2-deficient cells is due to a dysfunction of the cell-protective PI 3-kinase/protein kinase B (PKB)/ Bad signalling pathway, we determined the phosphorylation state of PKB and Bad. PKB contains a phosphorylation site at Ser ${ }^{473}$, which is supposedly either an autophosphorylation site or phosphorylated by another protein kinase, tentatively named PKB Ser ${ }^{473}$ kinase or PDK2 (Alessi et al., 1996; Persad et al., 2001; Hill et al., 2002). Phosphorylation of this site is always coupled to increased kinase activity (Alessi et al., 1996; Persad et al., 2001; Hill et al., 2002). Incubation of wild-type cells for $6 \mathrm{~h}$ in DMEM supplemented with 1\% FBS resulted in a considerable basal level of phospho-Ser ${ }^{473}$ PKB (Figure 2 inset, upper panel). This constitutive phosphorylation was drastically lower in SK-1-deficient cells, whereas in SK-2-deficient cells, phospho-Ser ${ }^{473}$ PKB was even amplified (Figure 2 inset, upper panel). Staurosporine stimulation decreased the amount of phospho-Ser ${ }^{473}$ PKB in wild-type cells, which is consistent with increased apoptosis. In SK-1-deficient cells, phospho-Ser ${ }^{473}$ PKB levels remained low after staurosporine treatment (Figure 2 inset, upper panel). Importantly, phospho-Ser ${ }^{473}$ PKB levels in SK-2-deficient cells were only slightly lower after staurosporine treatment and remained significantly higher than in wild-type cells (Figure 2 inset, upper panel). Total PKB levels were not altered in wild-type or

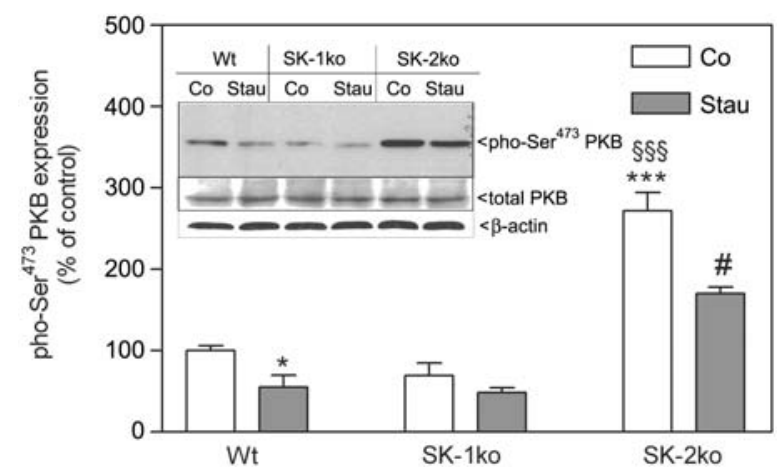

Figure 2 Effect of staurosporine on PKB expression and phosphorylation in wild-type, SK-1-deficient and SK-2-deficient mouse mesangial cells.

Quiescent mouse mesangial cells isolated from wild-type (Wt), SK-1-deficient (SK-1ko) or SK-2-deficient mice (SK-2ko) were stimulated for $6 \mathrm{~h}$ with either vehicle (Co) or staurosporine (stau, $10 \mathrm{nM}$ ) in the presence of $1 \%$ FBS. Then cell lysates containing $50 \mu \mathrm{g}$ of protein were separated by SDS-PAGE, transferred to nitrocellulose and subjected to Western blot analysis using antibodies against phospho-Ser ${ }^{473}$-PKB (inset, upper panel), total PKB (inset, middle panel), or $\beta$-actin (inset, lower panel) at dilutions of 1:1000, 1:1000 and 1:10 000, respectively. Bands were visualised by the ECL method according to the manufacturer's instructions, and were densitometrically evaluated. Data are presented as a percentage of the control and are mean $\pm S D(n=4)$. ${ }^{\star} p<0.05,{ }^{* \star *} p<0.001$ significantly different compared to wildtype control values, ${ }^{*} p<0.05$ compared to SK2ko vehicle-stimulated values, $\$ \$ \$ p<0.001$ compared to SK1ko vehiclestimulated values.
SK-1- or SK-2-depleted cells and did not change upon staurosporine stimulation (Figure 2 inset, middle panel). In addition, $\beta$-actin remained constant in the different cell lines and did not change upon stimulation (Figure 2 inset, lower panel).

Active PKB can phosphorylate Bad at Ser ${ }^{136}$ and thus inactivates the pro-apoptotic Bad, leading to cell protection (Datta and Brunet, 1999). We found that phosphorylation of Bad at $\mathrm{Ser}^{136}$ in the presence of $1 \%$ FBS was drastically decreased by staurosporine not only in wildtype cells, but also in SK-1-deficient cells, whereas in SK-2-deficient cells phosphorylation of Bad remained high and was hardly affected by staurosporine (Figure 3 ). Collectively, these data suggest that SK-1-deficient cells have a lower protective capacity due to disturbed PKB activation, whereas SK-2-deficient cells have a high protective capacity that, at least in part, is due to persistent PKB activation and Bad phosphorylation upon exposure to stress stimuli.

Since cell apoptosis may also be regulated by the expression levels of other anti-apoptotic factors, particularly Bcl-2 (Osford et al., 2004; Kim, 2005) and Bcl-X (Boise et al., 1993; Kim, 2005), we next investigated these factors. Interestingly, mouse mesangial cells lacking SK-2 expressed much higher levels of $\mathrm{Bcl}-\mathrm{X}_{\mathrm{L}}$ protein compared to either wild-type or SK-1-deficient cells (Figure 4A inset, upper panel). SK-1-deficient cells even exhibited slightly lower $\mathrm{BCl}-\mathrm{X}_{\mathrm{L}}$ expression compared to wild-type cells, which could contribute to the more apoptosis-prone state of these cells. In contrast, Bcl-2 protein expression did not significantly change in any of the cell lines (Figure 4A inset, lower panel). Staurosporine treatment of cells caused partial downregulation of $\mathrm{Bcl}-\mathrm{X}_{\mathrm{L}}$

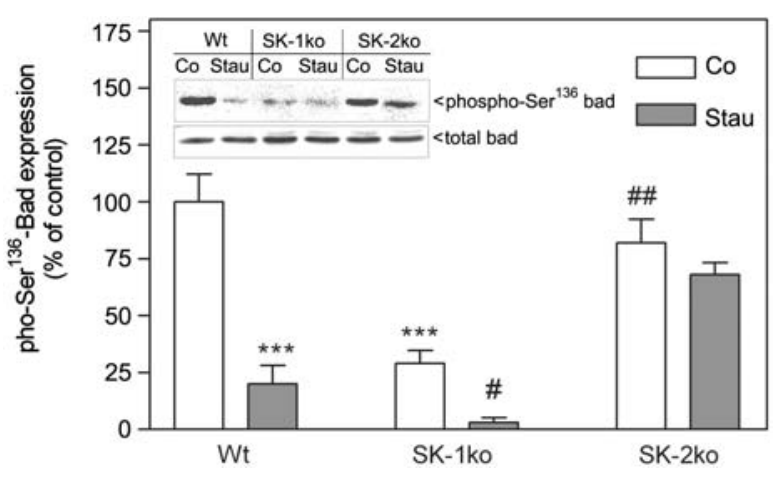

Figure 3 Effect of staurosporine on Bad expression and phosphorylation in wild-type, SK-1-deficient and SK-2-deficient mouse mesangial cells.

Quiescent mouse mesangial cells isolated from wild-type (Wt), SK-1-deficient (SK1ko) or SK-2-deficient mice (SK2ko) were stimulated for $6 \mathrm{~h}$ with either vehicle (Co) or staurosporine (stau, $10 \mathrm{~nm}$ ) in the presence of $1 \%$ FBS. Then cell lysates containing $50 \mu \mathrm{g}$ of protein were separated by SDS-PAGE, transferred to nitrocellulose and subjected to Western blot analysis using antibodies against either phospho-Ser ${ }^{136}$-Bad (inset, upper panel) or total Bad (inset, lower panel) at dilutions of 1:500 each. Bands were visualised by the ECL method according to the manufacturer's instructions, and were densitometrically evaluated. Data are presented as a percentage of the control and are mean $\pm S D$ $(n=4) .{ }^{* *} p<0.001$ significantly different compared to wild-type control values, ${ }^{\#} p<0.05,{ }^{\# \#} p<0.01$ compared to SK-1ko vehicle-stimulated values. 

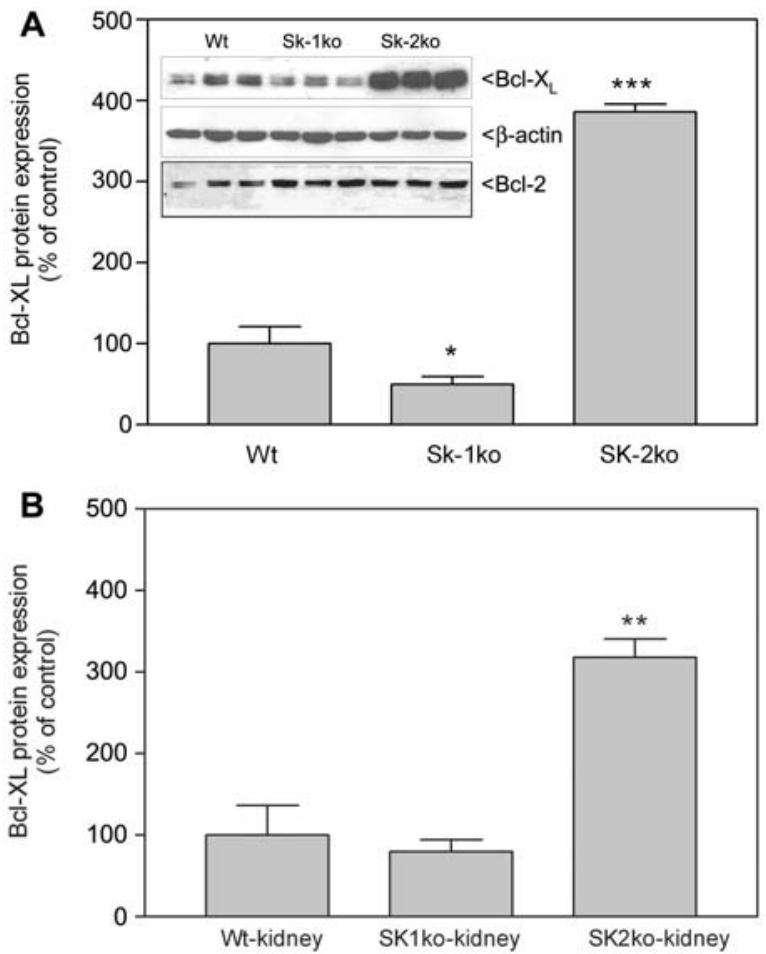

Figure 4 Protein expression profile of the anti-apoptotic factors $\mathrm{Bcl}-\mathrm{X}_{\mathrm{L}}$ and $\mathrm{Bcl}-2$ in wild-type, SK-1-deficient, and SK-2deficient mouse mesangial cells and whole kidney extracts.

Protein lysates from mouse mesangial cells (A) or whole kidneys (B) from wild-type (Wt), SK-1-deficient (SK-1ko) or SK-2-deficient mice (SK-2ko) were separated by SDS-PAGE, transferred to nitrocellulose and subjected to Western blot analysis using specific antibodies against $B c l-X_{L}$ (inset in $A$, upper panel; dilution 1:1000), $\beta$-actin (inset in $A$, middle panel; dilution 1:10 000), and $\mathrm{Bcl}-2$ (inset in $\mathrm{A}$, lower panel; dilution 1:500) as indicated. Bands were visualised by the ECL method according to the manufacturer's instructions and densitometrically evaluated. Densities corresponding to $\mathrm{Bcl}-\mathrm{X}_{\mathrm{L}}$ protein are depicted as percentage of control values and are mean $\pm S D(n=4) .{ }^{*} p<0.05$, ${ }^{* *} p<0.01$, ${ }^{* * *} p<0.001$ significantly different compared to corresponding wild-type control values. Insets in (A) show three out of four samples.

protein expression in all primary cell cultures $(63 \%$ in Wt cells, $80 \%$ in SK1ko cells, and $25 \%$ in SK2ko cells), although the effect in SK-2-deficient cells was small. Staurosporine had no effect on Bcl-2 expression (data not shown). These data confirm previous data in other cell types that also showed downregulation of $\mathrm{Bcl}-\mathrm{X}_{\mathrm{L}}$ by staurosporine (Giuliano et al., 2004) and other pro-apoptotic stimuli (Liu and Stein, 1997; Saltzman et al., 1998; Weinmann et al., 1999). Furthermore, cell lysates of whole kidneys from SK-2-deficient mice exhibited significantly enhanced protein expression of $B c l-X_{L}$ (Figure 4B), but not of Bcl-2 (data not shown). In SK-1-deficient kidney lysates, no significant changes in $\mathrm{Bcl}-\mathrm{X}_{\mathrm{L}}$ (Figure $4 \mathrm{~B}$ ) or $\mathrm{Bcl}-2$ protein levels (data not shown) were observed. Moreover, the increased $B c l-X_{L}$ expression in SK-2-deficient cells, but not in SK-1-deficient cells, was also reflected at the mRNA level (Figure 5). Again, Bcl-2 mRNA expression did not change in wild-type, SK-1deficient or SK-2-deficient mesangial cells (Figure 5).

Finally, to determine whether these changes in antiapoptotic factors can be attributed to the accumulation

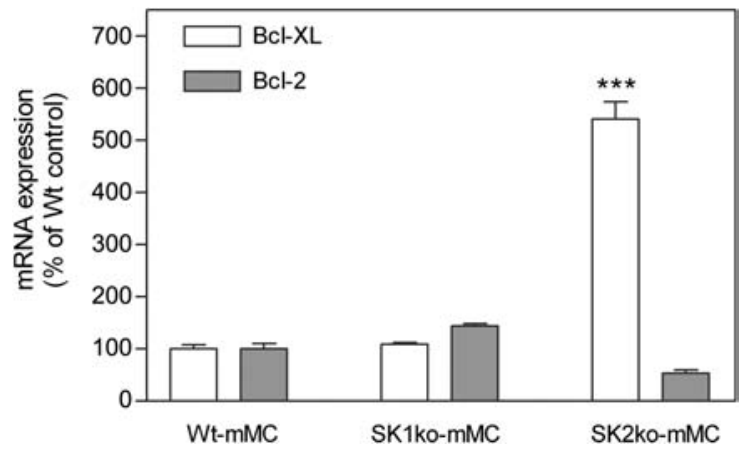

Figure $5 \mathrm{Bcl}-\mathrm{X}_{\mathrm{L}}$ and $\mathrm{Bcl}-2 \mathrm{mRNA}$ expression levels in mesangial cells from wild-type, SK-1-deficient and SK-2-deficient mice.

RNA extracts of mouse mesangial cells isolated from wild-type (Wt-mMC), SK-1-deficient (SK1 ko-mMC), or SK-2-deficient mice (SK2ko-mMC) were subjected to quantitative PCR analysis of $\mathrm{Bcl}-\mathrm{X}_{\mathrm{L}}$ (open columns), Bcl-2 (closed columns) and 18S RNA expression. $\Delta \Delta \mathrm{Ct}$ values were calculated using iQ5 Optical System Software Version 2.0 from Bio-Rad. Data are expressed as a percentage of wild-type expression levels and are mean $\pm S D$ $(n=4),{ }^{* \star} p<0.001$ significantly different compared to wild-type control values.

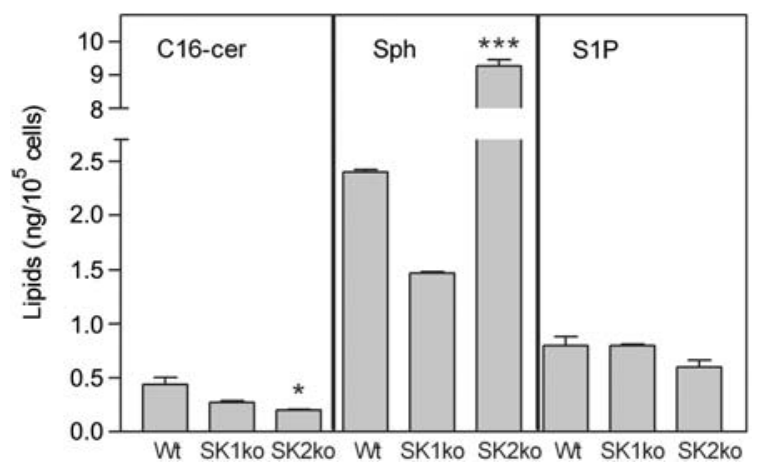

Figure 6 Quantification of S1P, sphingosine and C16-ceramide in wild-type, SK-1-deficient and SK-2-deficient mice.

Mouse mesangial cells were isolated from wild-type (Wt), SK-1deficient (SK1ko), or SK-2-deficient mice (SK2ko) for lipid extraction and then subjected to LC/MS/MS as described in the materials and methods section. Results are expressed as $\mathrm{ng} / 10^{5}$ cells of C16-ceramide (C16-cer), sphingosine (Sph), or S1P, and are mean $\pm \mathrm{SD}(\mathrm{n}=3) .{ }^{\star} p<0.05,{ }^{\star \star \star} p<0.001$ significantly different compared to wild-type control values.

of a certain sphingolipid species, we quantified the three main bioactive sphingolipids, C16-ceramide, sphingosine and S1P, in the three primary cell cultures. Surprisingly, neither SK-1-deficient nor SK-2-deficient cells showed a clear decrease in cellular S1P levels (Figure 6), suggesting that compensatory mechanisms may be involved. Only SK-2-deficient cells showed a drastic accumulation of sphingosine. The levels of $\mathrm{C} 16$-ceramide remained very low in all three cell cultures and even significantly decreased in SK-2-deficient cells compared to wild-type cells (Figure 6).

\section{Discussion}

In this study we show for the first time that SK-1 and SK2 in renal mesangial cells have opposite cellular functions 
in regulating cell survival and cell death. Lack of SK-1 causes increased sensitivity towards an apoptotic trigger, whereas lack of SK-2 renders the cells more resistant and protects them from undergoing apoptosis. This suggests that SK-1 protects cells, whereas SK-2, when active, may have pro-apoptotic potential.

It is well reported in the literature that the balance of the two sphingolipids ceramide and S1P determines the cell's fate to either proliferate or undergo apoptosis (Huwiler et al., 2000; Futerman and Hannun, 2004; Huwiler and Pfeilschifter, 2006). Much evidence has been presented in recent years indicating that S1P is both a mitogenic and a survival factor, whereas ceramide has pro-apoptotic potential (Huwiler et al., 2000; Futerman and Hannun, 2004; Huwiler and Pfeilschifter, 2006). However, our data now suggest that this concept does not accurately reflect reality. Although the two SKs theoretically generate the same product, i.e., S1P, they have opposite effects on cell survival. This suggests that the subcellular site of S1P generation, the duration and strength of signals generated, or potential interacting partner recruited, just to name a few possibilities, are critical for the cell response. It cannot be excluded that the differential effects observed are due to other functions of SKs independent of their kinase activities and S1P generation. This arises from our findings that cellular S1P levels hardly changed in SK-deficient cell cultures, although cell responses were strongly affected. Only in SK-2-deficient cells did sphingosine accumulate as expected. However, it is unlikely that this increase in sphingosine is responsible for the cell protective capacity in these cells, as sphingosine is normally considered a pro-apoptotic molecule (for a review see Huwiler et al., 2000). Previous studies by other groups also revealed unexpected results regarding sphingolipid levels in SK1- and SK-2-deficient mice and tissues. In this context, Zemann et al. (2006) reported that serum S1P levels in SK-2-deficient mice increased, but decreased by approximately $50 \%$ in SK-1-deficient mice. Moreover, Michaud et al. (2006) measured S1P levels in forepaw tissue and found only slight decreases in SK-1-deficient mice. Recently, Mizugishi et al. (2007) generated SphK1${ }^{\text {-SphK }}{ }^{+/-}$mice and investigated uterine decidualisation. When measuring S1P levels in uteri, there was no difference between wild-type and SphK1-/-SphK2 $2^{+/}$mice. In contrast, S1P levels measured in SK-1-deficient or SK2-deficient embryonic E11.5 tissue was drastically lower, and completely absent in double knockout embryonic tissue. However, this was not accompanied by an accumulation of sphingosine (Mizugishi et al., 2005).

In a previous study using cultured fibroblasts and HEK 293 cells, Maceyka et al. (2005) proposed opposite regulatory effects of SK-1 and SK-2 on ceramide biosynthesis. By downregulating SK-2 by siRNA, they showed a decrease in ceramide formation, whereas downregulation of SK-1 by siRNA resulted in increased ceramide formation. Our data did not reveal increased C16-ceramide levels in SK-1-deficient cells, but we found significantly lower levels in SK-2-deficient cells (Figure 6). However, the C16-ceramide levels measured were generally very low and it is not clear whether such small changes are responsible for the effects observed. Still, it may be argued that C16-ceramide is only one ceramide subspecies, albeit the most abundant, and higher levels are reached when summing all ceramide subspecies and the decrease in SK-2-deficient cells is more drastic.

So far, few data are available on the subcellular localisation of the two SK subtypes. In this context, Kleuser et al. (2001) showed that in Swiss 3T3 fibroblasts overexpressing green fluorescence protein-coupled SK-1, the enzyme was equally localised in the cytoplasm and in the nucleus and that the nuclear fraction of SK-1 was activated upon PDGF stimulation. Indeed, sequence analysis of SK-1 revealed a nuclear export signal that directs export of SK-1 from the nucleus to the cytoplasm and suggests constant 'shuttling' of the enzyme (Inagaki et al., 2003). Upon activation, cytoplasmic SK-1 can also translocate to the plasma membrane, which requires phosphorylation of the enzyme by ERK (Pitson et al., 2005).

A nuclear localisation signal (NLS) has been identified at the N-terminal sequence of SK-2 (Igarashi et al., 2003), which actively directs SK-2 to the nucleus. Functionally, it was shown that the nuclear localisation of SK-2 is coupled to inhibition of DNA synthesis, since mutation of two nucleotides ( $\mathrm{Arg}^{93}$ and $\mathrm{Arg}^{94}$ ) of the NLS of murine SK-2 abolished the inhibitory effect on DNA synthesis. In addition, the generation of a 'chimeric' SK-1 containing the NLS of SK-2 at its N-terminus was able to mimic the inhibitory effect on DNA synthesis (Igarashi et al., 2003). Moreover, it was shown that nuclear SK-2 can be phosphorylated by the protein kinase $\mathrm{D}$, which is also known as protein kinase $\mathrm{C}-\mu$, resulting in export of SK-2 to the cytoplasm (Ding et al., 2007). All these data suggest that there are subcellular pools of sphingolipids and that the knockout of either SK-1 or SK-2 may lead to subcellular and local changes in sphingolipid levels that are not detectable using our total cell lipid extraction method.

The mechanisms by which S1P acts as a survival factor may include various overlapping or non-overlapping signalling cascades. In particular, activation of the PI 3-kinase/PKB pathway by S1P, as reported for various cell types (Igarashi et al., 2001; Robert et al., 2001; Davaille et al., 2002) including renal mesangial cells (Xin et al., 2004), may strongly promote cell survival mechanisms. Activated PKB phosphorylates Bad at Ser ${ }^{136}$ and thus renders this pro-apoptotic factor inactive (BlumeJensen et al., 1998; Datta and Brunet, 1999).

Our data suggest that SK-1 positively regulates the cell-protective PKB/Bad pathway. Consequently, SK-1deficient cells have drastically lower levels of phosphorylated and hence activated PKB and its substrate Bad. Whether this mechanistically involves an autocrine mode of action of S1P via secretion and subsequent activation of cell-surface S1P receptors or an intracellular action of $\mathrm{S} 1 \mathrm{P}$, or is even independent of S1P, remains unclear. So far, most evidence in the literature supports S1P receptor-mediated activation of the PI3K/PKB cascade. However, intracellular S1P can activate signal transduction and acutely triggers intracellular $\mathrm{Ca}^{2+}$ mobilisation (Meyer zu Heringdorf et al., 2003) and stimulates cell proliferation of fibroblasts (van Brocklyn et al., 1998).

In contrast, cells lacking SK-2 have a constitutively active PKB/Bad pathway (Figures 2 and 3 ) and are more 
resistant to apoptotic stimuli (Figure 1). In addition, these cells have highly upregulated expression of the antiapoptotic $\mathrm{Bcl}-2$ family member $\mathrm{Bcl}-\mathrm{X}_{\mathrm{L}}$. How the absence of SK-2 is mechanistically coupled to PKB/Bad activation and $\mathrm{BCl}-\mathrm{X}_{\mathrm{L}}$ upregulation is unknown, but strongly points to a nuclear suppressive effect of SK-2 on cell signalling and gene transcription that is lost upon SK-2 depletion. In this context, it is known that $\mathrm{Bcl}-\mathrm{X}_{\mathrm{L}}$ expression is upregulated by many anti-apoptotic stimuli (Boise et al., 1993; Sevilla et al., 2001; Kim, 2005) and that this is partially due to transcriptional activation of the gene. The $\mathrm{Bcl}-\mathrm{X}_{\mathrm{L}}$ promoter has been cloned (Grillot et al., 1997; MacCarthy-Morrogh et al., 2000) and sequence analyses revealed various binding sites for transcription factors such as NF-кB, Ets, STAT and AP1 (Sevilla et al., 2001). Thus, it is tempting to speculate that one of the $\mathrm{Bcl}-\mathrm{X}_{\mathrm{L}}$ regulating transcription factors is also constitutively activated in SK-2-deficient cells. Clearly, further studies are needed to address this in detail. In addition, it was reported that ERK and PKB/Akt cooperatively upregulate Bcl$X_{L}$ expression (Suzuki et al., 1998). In view of this study, the increased expression of $\mathrm{Bcl}-\mathrm{X}_{\mathrm{L}}$ observed in SK-2deficient cells could also be a consequence of the increase in PKB activation. It is well known that PKB couples to various transcription factors including the forkhead transcription factor FOXO, the tumour suppressor p53, and NF-kB (Brunet et al., 2001).

Limaye et al. (2005) showed that S1P generated by SK-1 overexpression in endothelial cells exerted a cell protective effect due to activation of PKB and specific upregulation of $\mathrm{Bcl}-2$. On the other hand, it was shown that cellular overexpression of $\mathrm{Bcl}-2$ in A-375 cells markedly stimulated SphK1 expression and activity, whereas downregulation of Bcl-2 decreased SphK1 expression (Bektas et al., 2005). The relationship between $\mathrm{Bcl}-2$ and SK-1 seems to be cell-type-specific, because no significant changes in Bcl-2 mRNA or protein expression were caused by either SK-1 or SK-2 depletion in renal mesangial cells (Figure 4A) and, importantly, in whole kidney (data not shown). Moreover, in human T-lymphoblastoma cells, the cell protective effect of S1P was independent of Bcl-2 and Bcl-X (Goetzl et al., 1999).

In summary, our data demonstrate that SK-1 and SK-2 have opposite effects on stress-induced apoptosis in renal mesangial cells. The absence of SK-1 makes cells prone to apoptosis, whereas the absence of SK-2 protects cells from undergoing apoptosis. This provides an example of how a specific signal, i.e., the generation of S1P, can be interpreted differentially at the level of gene expression and functional cell response. A future challenge will be to elucidate the structure of wiring of the SphK/S1P signalling pathway to its physiological partners in the cell and finally to determine the functional consequences of these interactions.

\section{Materials and methods}

\section{Chemicals}

Secondary anti-rabbit and anti-mouse horseradish peroxidasecoupled IgGs, Hyperfilm MP, and enhanced chemiluminescence $(E C L)$ reagents were from GE Health Care Systems GmbH (Frei- burg, Germany). Antibodies against active caspase-3, phosphoSer ${ }^{136}$-Bad, total Bad, phospho-Ser ${ }^{473}-\mathrm{PKB} / \mathrm{Akt}, \mathrm{Bcl}-\mathrm{X}_{\mathrm{L}}$, and $\mathrm{Bcl}-2$ were from Cell Signaling (Frankfurt, Germany). Total PKB/ Akt-1 was from Santa Cruz Biotechnology (Heidelberg, Germany). $\beta$-Actin (clone AC-15) antibody and staurosporine were from Sigma Aldrich Fine Chemicals (St. Louis, MO, USA). The DNA fragmentation ELISA was from Roche Diagnostics (Mannheim, Germany) and the annexin V-FITC/7-aminoactinomycin (7AAD) apoptosis assay kit was from Beckman Coulter (Krefeld, Germany). All cell culture nutrients were from Life Technologies (Karlsruhe, Germany).

\section{Cell culture}

SK-1-deficient and SK-2-deficient mice were generated by Genoway (Lyon, France) and backcrossed to C57BL/6. Mouse renal mesangial cells were isolated from C57BL/6 control mice and SK-1-deficient and SK-2-deficient mice as previously described (Klawitter et al., 2007). Outgrown mesangial cells were subcultured and further used up to passage 8 . Cells were characterised by positive staining for smooth muscle $\alpha$-actin and negative staining for cytokeratin (to exclude epithelial cell contamination). The growth medium was RPMI containing 15\% fetal bovine serum (FBS), $10 \mathrm{~mm}$ HEPES, pH 7.4, $100 \mathrm{U} / \mathrm{ml}$ penicillin, $100 \mu \mathrm{g} / \mathrm{ml}$ streptomycin, $6 \mu \mathrm{g} / \mathrm{ml}$ bovine insulin, $5 \mu \mathrm{g} / \mathrm{ml}$ transferrin, $5 \mathrm{ng} / \mathrm{ml}$ sodium selenite and $4.5 \mu \mathrm{g} / \mathrm{ml} \beta$-mercaptoethanol.

\section{Cell stimulation and Western blot analysis}

Confluent mesangial cells in 60-mm-diameter dishes were rendered quiescent by incubation for 1 day in serum-free Dulbecco's modified Eagle medium (DMEM) containing $0.1 \mathrm{mg} / \mathrm{ml}$ fatty acid-free bovine serum albumin (BSA) and $1 \%$ FBS. Cells were then stimulated as indicated. To stop the stimulation, the medium was withdrawn and the cells were washed once with icecold phosphate-buffered saline (PBS) solution. Cells were scraped into ice-cold lysis buffer $(50 \mathrm{~mm}$ Tris- $\mathrm{HCl}, \mathrm{pH} 7.4$, $150 \mathrm{~mm} \mathrm{NaCl}, 10 \%$ glycerol, 1\% Triton X-100, 2 mm EDTA, 2 mM EGTA, $40 \mathrm{~mm} \beta$-glycerophosphate, $50 \mathrm{~mm}$ sodium fluoride, $10 \mu \mathrm{g} / \mathrm{ml}$ leupeptin, $10 \mu \mathrm{g} / \mathrm{ml}$ pepstatin A, $1 \mathrm{~mm}$ phenylmethylsulfonyl fluoride) and homogenised by 10 passes through a 26G needle fitted to a $1-\mathrm{ml}$ syringe. Lysates were then centrifuged for $10 \mathrm{~min}$ at $13000 \mathrm{~g}$ and the supernatant was analysed for protein content. Equal amounts of protein $(50 \mu \mathrm{g})$ were separated by SDS-PAGE and transferred to nitrocellulose membranes and subjected to Western blot analysis as previously described (Huwiler et al., 1995).

\section{Quantitative real-time PCR}

Samples of $3 \mu \mathrm{g}$ of total RNA isolated using TRIZOL reagent were subjected to RT-PCR (first-strand synthesis kit, MBI, Vilnius, Lithuania) using a random hexamer primer for amplification. The following primer sequences were used: mouse SK-1, forward 5'-CCT GGA GGA GGC AGA GAT AAC C-3', reverse 5'CCG TTC CAT TAG CCC ATT CAC C-3'; mouse SK-2, forward 5'-GCA CGG CGA GTT TGG TTC C-3', reverse 5'-TGT ATG TGT AGG GCT TGT GTT GTG-3'; mouse Bcl- $X_{L}$, forward 5'-TCT GAA TGA CCA CCT AGA GCC TTG-3', reverse 5'-AGA ACC ACA CCA GCC ACA GTC-3'; mouse Bcl-2, forward 5'-TCC TTC CAG CCT GAG AGC AAC-3', reverse 5'-CAC GAC GGT AGC GAC GAG AG-3'; and mouse 18S RNA, forward 5'-CGA TTC CGT GGG TGG TGG TG-3', reverse 5'-CAT GCC AGA GTC TCG TTC GTT ATC-3'. The reporter dye was SYBR green. The PCR buffer was from Bio-Rad (Munich, Germany). After cDNA synthesis, $0.2 \mu \mathrm{l}$ of the product $(0.02 \mu \mathrm{l}$ for $18 \mathrm{~S}$ RNA) was used for further analysis. Runs were performed on an iQ5 Cycler (Bio-Rad) at 
$95^{\circ} \mathrm{C}$ for $15 \mathrm{~min}$, followed by 40 cycles of $95^{\circ} \mathrm{C}$ for $15 \mathrm{~s}$ and $58^{\circ} \mathrm{C}$ for $1 \mathrm{~min}$. iQ5 Optical System Software Version 2.0 from Bio-Rad was used to analyse real-time and endpoint fluorescence. Fold induction values were obtained according to the $\Delta \Delta \mathrm{C}_{\mathrm{T}}$ method.

\section{DNA fragmentation ELISA}

Cells in 6-well plates were stimulated as indicated and removed for DNA fragmentation ELISA according to the manufacturer's instructions.

\section{Flow cytometric analysis of cell death}

Exposure of phosphatidyl serine (PS) on the extracellular surface of the plasma membrane, which is an early marker of apoptotic cells, was determined using an annexin-V-FITC/7-aminoactinomycin (7AAD) apoptosis assay kit. Quiescent mesangial cells in 6 -well plates were stimulated as indicated. To stop the stimulation, the medium was withdrawn and the cells were washed once with ice-cold PBS. Cells were then harvested by trypsinisation and cell pellets were resuspended at a concentration of $6 \times 10^{6} \mathrm{cell} / \mathrm{s} / \mathrm{ml}$ binding buffer. PS-expressing cells were stained with annexin-V FITC, and the DNA of apoptotic and necrotic cells was stained with 7AAD according to the manufacturer's instructions. Cytofluorometric analyses were performed using FACSCalibur (Becton Dickinson, San Jose, CA, USA). A total of 10000 cells was collected for each sample. Viable cells were defined as annexin V-FITC-negative and 7AAD-negative cells. Apoptotic cells were defined as annexin V-FITC-positive and 7AAD-negative, and necrotic cells as annexin V-FITC-positive and 7AAD-positive cells. Analyses of the multivariate data were performed using CELLQuest, which is part of the FACSCalibur operating system.

\section{Sphingolipid quantification by LC/MS/MS}

Confluent cells in 6-well plates were removed for lipid extraction according to Bligh and Dyer (1959) and parallel cell counting. As internal standards, C17-ceramide $(5 \mathrm{ng} / \mathrm{ml}), \mathrm{C} 17-\mathrm{S} 1 \mathrm{P}(20 \mathrm{ng} / \mathrm{ml})$ and C17-sphingosine (20 ng/ml) (Avanti Polar Lipids Inc., Alabaster, AL, USA) were added to the lipid extraction samples. Dried lipids were redissolved in dimethylsulfoxide including 2\% $\mathrm{HCl}$ and subjected to LC/MS/MS according to Schmidt et al. (2006).

\section{Statistical analysis}

Statistical analysis was performed by one-way analysis of variance (ANOVA). For multiple comparisons with the same control group, the limit of significance was divided by the number of comparisons according to Bonferroni.

\section{Acknowledgments}

This work was supported by the Swiss National Foundation (3100A0-111806), the German Research Foundation (FOG784, GRK757/2, GRK1172, HU842/4-1, PF361/6-1, EXC147), the Norwegian Research Council and Avexxin AS, the European Community (FP6: LSHM-CT-2004-005033), the Wilhelm SanderFoundation, the Novartis Foundation and Hochschulstiftung der Universität Bern.

\section{References}

Alemany, R., van Koppen, C.J., Danneberg, K., ter Braak, M., and Meyer zu Heringdorf, D. (2007). Regulation and functional roles of sphingosine kinases. Naunyn-Schmiedeberg's Arch. Pharmacol. 374, 413-428.

Alessi, D.R., Andjelkovic, M., Caudwell, B., Cron, P., Morrice, N., Cohen, P., and Hemmings, B.A. (1996). Mechanism of activation of protein kinase $B$ by insulin and IGF-1. EMBO J. 15, 6541-6551.

Bektas, M., Jolly, P.S., Müller, C., Eberle, J., Spiegel, S., and Geilen, C.C. (2005). Sphingosine kinase activity counteracts ceramide-mediated cell death in human melanoma cells: role of Bcl-2 expression. Oncogene 24, 178-187.

Bligh, E.G. and Dyer, W.J. (1959). A rapid method of total lipid extraction and purification. Can. J. Biochem. Physiol. 37, 911-917.

Blume-Jensen, P., Janknecht, R., and Hunter, T. (1998). The kit receptor promotes cell survival via activation of PI 3-kinase and subsequent Akt-mediated phosphorylation of $\mathrm{Bad}$ on Ser136. Curr. Biol. 8, 779-782.

Boatright, K.M. and Salvesen, G.S. (2003). Mechanisms of caspase activation. Curr. Opin. Cell Biol. 15, 725-731.

Boise, L.H., Gonzalez-Garcia, M., Postema, C.E., Ding, L., Lindsten, T., Turka, L.A., Mao, X., Nunez, G., and Thompson, C.B. (1993). Bcl-x, a bcl-2-related gene that functions as a dominant regulator of apoptotic cell death. Cell 74, 597-608.

Brunet, A., Datta, S.R., and Greenberg, M.E. (2001). Transcription-dependent and -independent control of neuronal survival by the PI3K-Akt signaling pathway. Curr. Opin. Neurobiol. 11, 297-305.

Datta, S.R. and Brunet, A. (1999). Cellular survival: a play in three Akts. Genes Dev. 13, 2905-2927.

Davaille, J., Li, J., Mallat, A., and Lotersztain, S. (2002). Sphingosine 1-phosphate triggers both apoptotic and survival signals for human hepatic myofibroblasts. J. Biol. Chem. 277, 37323-37330.

Ding, G., Sonoda, H., Yu, H., Kajimoto, T., Goparaju, S.K., Jahangeer, S., Okada, T., and Nakamura, S. (2007). Protein kinase D-mediated phosphorylation and nuclear export of sphingosine kinase 2. J. Biol. Chem. 282, 27493-27502.

Döll, F., Pfeilschifter, J., and Huwiler, A. (2005). The epidermal growth factor stimulates sphingosine kinase-1 expression and activity in the human mammary carcinoma cell line MCF7. Biochim. Biophys. Acta 1738, 72-81.

Döll, F., Pfeilschifter, J., and Huwiler, A. (2007). Prolactin upregulates sphingosine kinase-1 expression and activity in the human breast cancer cell line MCF7 and triggers enhanced proliferation and migration. Endocr. Relat. Cancer 14, 325335.

French, K.J., Schrecengost, R.S., Lee, B.D., Zhuang, Y., Smith, S.N., Eberly, J.L., Yun, J.K., and Smith, C.D. (2003). Discovery and evaluation of inhibitors of human sphingosine kinase. Cancer Res. 63, 5962-5969.

French, K.J., Upson, J.J., Keller, S.N., Zhuang, Y., Yun, J.K., and Smith, C.D. (2006). Antitumor activity of sphingosine kinase inhibitors. J. Pharmacol. Exp. Ther. 318, 596-603.

Futerman, A.H. and Hannun, Y.A. (2004). The complex life of simple sphingolipids. EMBO Rep. 5, 777-782.

Giuliano, M., Bellavia, G., Lauricella, M., D’Anneo, A., Vassallo, B., Vento, R., and Tesoriere, G. (2004). Staurosporineinduced apoptosis in Chang liver cells is associated with down-regulation of Bcl-2 and Bcl-XL. Int. J. Mol. Med. 13, 565-571.

Goetzl, E.J., Kong, Y., and Mei, B. (1999). Lysophosphatidic acid and sphingosine 1-phosphate protection of $T$ cells from apoptosis in association with suppression of Bax. J. Immunol. 162, 2049-2056.

Grillot, D.A., Gonzalez-Garcia, M., Ekhterae, D., Duan, L., Inohara, N., Ohta, S., Seldin, M.F., and Nunez, G. (1997). Genomic organization, promoter region analysis, and chro- 
mosome localization of the mouse bcl-x gene. J. Immunol. 158, 4750-4757.

Hait, N.C., Oskeritzian, C.A., Paugh, S.W., Milstien, S., and Spiegel, S. (2006). Sphingosine kinases, sphingosine 1-phosphate, apoptosis and diseases. Biochim. Biophys. Acta 1758, 2016-2026.

Hill, M.M., Feng, J., and Hemmings, B.A. (2002). Identification of a plasma membrane Raft-associated PKB Ser ${ }^{473}$ kinase activity that is distinct from ILK and PDK1. Curr. Biol. 12, 1251-1255.

Huwiler, A. and Pfeilschifter, J. (2006). Altering the sphingosine1-phosphate/ceramide balance: a promising approach for tumor therapy. Curr. Pharm. Des. 12, 4625-4635.

Huwiler, A., Stabel, S., Fabbro, D., and Pfeilschifter, J. (1995). Platelet-derived growth factor and angiotensin II stimulate the mitogen-activated protein kinase cascade in renal mesangial cells: comparison of hypertrophic and hyperplastic agonists. Biochem. J. 305, 777-784.

Huwiler, A., Kolter, T., Pfeilschifter, J., and Sandhoff, K. (2000). Physiology and pathophysiology of sphingolipid metabolism and signaling. Biochim. Biophys. Acta 1485, 63-99.

Igarashi, J., Bernier, S.G., and Michel, T. (2001). Sphingosine 1phosphate and activation of endothelial nitric-oxide synthase. differential regulation of Akt and MAP kinase pathways by EDG and bradykinin receptors in vascular endothelial cells. J. Biol. Chem. 276, 12420-12426.

Igarashi, N., Okada, T., Hayashi, S., Fujita, T., Jahangeer, S., and Nakamura, S. (2003). Sphingosine kinase 2 is a nuclear protein and inhibits DNA synthesis. J. Biol. Chem. 278, 4683246839.

Inagaki, Y., Li, P.Y., Wada, A., Mitsutake, S., and Igarashi, Y. (2003). Identification of functional nuclear export sequences in human sphingosine kinase 1. Biochem. Biophys. Res. Commun. 311, 168-173.

$\mathrm{Kim}, \mathrm{R}$. (2005). Unknotting the roles of Bcl-2 and Bcl-xL in cell death. Biochem. Biophys. Res. Commun. 333, 336-343.

Klawitter, S., Hofmann, L.P., Pfeilschifter, J., and Huwiler, A. (2007). Extracellular nucleotides induce migration of renal mesangial cells by upregulating sphingosine kinase- 1 expression and activity. Br. J. Pharmacol. 150, 271-280.

Kleuser, B., Maceyka, M., Milstien, S., and Spiegel, S. (2001). Stimulation of nuclear sphingosine kinase activity by plateletderived growth factor. FEBS Lett. 503, 85-90.

Limaye, V., Li, X., Hahn, C., Xia, P., Berndt, M.C., Vadas, M.A., and Gamble, J.R. (2005). Sphingosine kinase-1 enhances endothelial cell survival through a PECAM-1-dependent activation of $\mathrm{Pl}-3 \mathrm{~K} / \mathrm{Akt}$ and regulation of $\mathrm{Bcl}-2$ family members. Blood 105, 3169-3177.

Liu, Q.Y. and Stein, C.A. (1997). Taxol and estramustine-induced modulation of human prostate cancer cell apoptosis via alteration in bcl-xL and bak expression. Clin. Cancer Res. 3, 2039-2046.

Liu, H., Toman, R.E., Goparaju, S.K., Maceyka, M., Nava, V.E., Sankala, H., Payne, S.G., Bektas, M., Ishii, I., Chun, J., Milstien, S., and Spiegel, S. (2003). Sphingosine kinase type 2 is a putative $\mathrm{BH} 3-o n l y$ protein that induces apoptosis. J. Biol. Chem. 278, 40330-40336.

MacCarthy-Morrogh, L., Wood, L., Brimmell, M., Johnson, P.W., and Packham, G. (2000). Identification of a novel human BCL-X promoter and exon. Oncogene 19, 5534-5538.

Maceyka, M., Sankala, H., Hait, N.C., Le Stunff, H., Liu, H., Toman, R., Collier, C., Zhang, M., Satin, L.S., Merrill, A.H. Jr., Milstien, S., and Spiegel, S. (2005). SphK1 and SphK2, sphingosine kinase isoenzymes with opposing functions in sphingolipid metabolism. J. Biol. Chem. 280, 37118-37129.

Meyer zu Heringdorf, D., Liliom, K., Schaefer, M., Danneberg, K., Jaggar, J.H., Tigyi, G., and Jakobs, K.H. (2003). Photolysis of intracellular caged sphingosine-1-phosphate causes $\mathrm{Ca}^{2+}$ mobilization independently of G-protein-coupled receptors. FEBS Lett. 554, 443-449.
Michaud, J., Kohno, M., Proia, R.L., and Hla, T. (2006). Normal acute and chronic inflammatory responses in sphingosine kinase 1 knockout mice. FEBS Lett. 580, 4607-4612.

Mizugishi, K., Yamashita, T., Olivera, A., Miller, G.F., Spiegel, S., and Proia, R.L. (2005). Essential role for sphingosine kinases in neural and vascular development. Mol. Cell. Biol. 25, 11113-11121.

Mizugishi, K., Li, C., Olivera, A., Bielawska, A., Deng, C.X., and Proia, R.L. (2007). Maternal disturbance in activated sphingolipid metabolism causes pregnancy loss in mice. J. Clin. Invest. 117, 2993-3006.

Okada, T., Ding, G., Sonoda, H., Kajimoto, T., Haga, Y., Khosrowbeygi, A., Gao, S., Miwa, N., Jahangeer, S., and Nakamura, S. (2005). Involvement of $\mathrm{N}$-terminal-extended form of sphingosine kinase 2 in serum-dependent regulation of cell proliferation and apoptosis. J. Biol. Chem. 280, 3631836325.

Osford, S.M., Daallman, C.L., Johnson, P.W., Ganesan, A., and Packham, G. (2004). Current strategies to target the antiapoptotic Bcl-2 protein in cancer cells. Curr. Med. Chem. 11, 1031-1039.

Persad, S., Attwell, S., Gray, V., Mawji, N., Deng, J.T., Leung, D., Yan, J., Sanghera, J., Walsh, M.P., and Dedhar, S. (2001). Regulation of protein kinase B/Akt-serine 473 phosphorylation by integrin-linked kinase: critical roles for kinase activity and amino acids arginine 211 and serine 343. J. Biol. Chem. 276, 27462-27469.

Pitson, S.M., Xia, P., Leclercq, T.M., Moretti, P.A., Zebol, J.R., Lynn, H.E., Wattenberg, B.W., and Vadas, M.A. (2005). Phosphorylation-dependent translocation of sphingosine kinase to the plasma membrane drives its oncogenic signalling. J. Exp. Med. 201, 49-54.

Robert, P., Tsui, P., Laville, M.P., Livi, G.P., Sarau, H.M., Bril, A., and Berrebi-Bertrand, I. (2001). EDG1 receptor stimulation leads to cardiac hypertrophy in rat neonatal myocytes. J. Mol. Cell. Cardiol. 33, 1589-1606.

Saltzman, A., Munro, R., Searfoss, G., Franks, C., Jaye, M., and Ivashchenko, Y. (1998). Transforming growth factor- $\beta$-mediated apoptosis in the Ramos B-lymphoma cell line is accompanied by caspase activation and $\mathrm{Bcl}-\mathrm{XL}$ downregulation. Exp. Cell Res. 242, 244-254.

Schmidt, H., Schmidt, R., and Geisslinger, G. (2006). LC-MS/ MS-analysis of sphingosine-1-phosphate and related compounds in plasma samples. Prostaglandins Other Lipid Mediat. 81, 162-170.

Sevilla, L., Zaldumbide, A., Pognonec, P., and Boulukos, K.E. (2001). Transcriptional regulation of the bcl-x gene encoding the anti-apoptotic $\mathrm{Bcl}-\mathrm{xL}$ protein by Ets, Rel/NF-kB, STAT and AP1 transcription factor families. Histol. Histopathol. 16, 595-601.

Suzuki, J., Kaziro, Y., and Koide, H. (1998). Synergistic action of R-Ras and IGF-1 on Bcl-xL expression and caspase-3 inhibition in BaF3 cells: R-Ras and IGF-1 control distinct antiapoptotic kinase pathways. FEBS Lett. 437, 112-116.

van Brocklyn, J.R., Lee, M.J., Menzeleev, R., Olivera, A., Edsall, L., Cuvillier, O., Thomas, D.M., Coopman, P.J., Thangada, S., Liu, C.H., et al. (1998). Dual actions of sphingosine-1-phosphate: extracellular through the Gi-coupled receptor Edg-1 and intracellular to regulate proliferation and survival. J. Cell. Biol. 142, 229-240.

Weinmann, P., Gaehtgens, P., and Walzog, B. (1999). Bcl-XI- and Bax- $\alpha$-mediated regulation of apoptosis of human neutrophils via caspase-3. Blood 93, 3106-3115.

Xin, C., Ren, S., Kleuser, B., Shabahang, S., Eberhardt, W., Radeke, H., Schäfer-Korting, M., Pfeilschifter, J., and Huwiler, A. (2004). Sphingosine 1-phosphate cross-activates the Smad signaling cascade and mimics transforming growth factor- $\beta$-induced cell responses. J. Biol. Chem. 279, 3525535262.

Yue, T.L., Wang, C., Romanic, A.M., Kikly, K., Keller, P., De Wolf, W.E. Jr., Hart, T.K., Thomas, H.C., Storer, B., Gu, J.L., et al. (1998). Staurosporine-induced apoptosis in cardiomyocytes: 
a potential role of caspase-3. J. Mol. Cell. Cardiol. 30, 495507.

Zemann, B., Kinzel, B., Müller, M., Reuschel, R., Mechtcheriakova, D., Urtz, N., Bornancin, F., Baumruker, T., and Billich, A. (2006). Sphingosine kinase type 2 is essential for lympho- penia induced by the immunomodulatory drug FTY720. Blood 107, 1454-1458.

Received May 26, 2008; accepted August 1, 2008 